\title{
You Don't Have to Be Infected to Suffer: COVID-19 and Racial Disparities in Severe Maternal Morbidity and Mortality
}

\author{
Howard Minkoff, MD ${ }^{1}$ \\ ${ }^{1}$ Department of Obstetrics and Gynecology, Maimonides Medical \\ Center and SUNY Downstate, Brooklyn, New York \\ Am J Perinatol 2020;37:1052-1054.
}

Address for correspondence Howard Minkoff, MD, SUNY Downstate Medical Center, 445 Lenox Road, Brooklyn, NY 11203 (e-mail: hminkoff@maimonidesmed.org).

\begin{abstract}
Keywords

- disparity

- COVID-19

- race

- maternal mortality

Both coronavirus disease 2019 (COVID-19) and maternal mortality disproportionately affect minorities. However, direct viral infection is not the only way that the former can affect the latter. Most adverse maternal events that end in hospitals have their genesis upstream in communities. Hospitals often represent a last opportunity to reverse a process that begins at a remove in space and time. The COVID-19 pandemic did not create these upstream injuries, but it has brought them to national attention, exacerbated them, and highlighted the need for health care providers to move out of the footprint of their institutions. The breach between community events that seed morbidity and hospitals that attempt rescues has grown in recent years, as the gap between rich and poor has grown and as maternity services in minority communities have closed. COVID-19 has become yet another barrier. For example, professional organizations have recommended a reduced number of prenatal visits, and the platforms hospitals use to substitute for some of these visits are not helpful to people who either lack the technology or the safe space in which to have confidential conversations with providers. Despite these challenges, there are opportunities for departments of obstetrics and gynecology. Community-based organizations including legal professionals, health-home coordinators, and advocacy groups, surround almost every hospital, and can be willing partners with interested departments. COVID-19 has made it clearer than ever that it is time to step out of the footprint of our institutions, and to recognize that the need to find upstream opportunities to prevent downstream tragedies.
\end{abstract}

\section{Key Points}

- COVID-19 will exacerbate disparities in perinatal outcomes.

- The virus, per se, is not the pandemic's biggest threat to the health of minority women.

- The solution to maternal mortality cannot be found within the walls of hospitals.

The disproportionate number of coronavirus disease 2019 (COVID-19)-related deaths suffered by minorities has been widely reported, and it mirrors what is known about maternal mortality. Accordingly, COVID-19 infections may marginally increase disparities in maternal mortality. However, even if no women were infected, the COVID-19 pandemic could still exacerbate disparities in maternal outcomes. As such, it highlights where much of the solution to disparities must lie. received

June 6, 2020

accepted

June 8,2020

published online

June 25, 2020
Copyright $\odot 2020$ by Thieme Medical

Publishers, Inc., 333 Seventh Avenue, New York, NY 10001, USA. Tel: $+1(212) 760-0888$
DOI https://doi.org/ 10.1055/s-0040-1713852. ISSN 0735-1631. 
Historically, efforts to reduce maternal mortality have focused on creating safer inpatient experiences. By developing algorithms, encouraging teamwork and drills and creating simulations and regionalization, the treatment of hemorrhage, hypertension, deep venous thrombosis, and sepsis has improved. However, a careful look at deaths and serious morbidities in 2020 makes the singular focus on inpatient, that is, downstream events hard to justify. In reality, the attention paid to events in the hospital is in large part because that is where physicians practice. It is not because the etiology and earlier opportunities to intercede do not exist elsewhere. The breach between upstream (in community) events that seed morbidity and downstream (in hospital) interventions that try to reverse the course of disease, has grown through the years as the gap between rich and poor has grown, and as maternity services in minority communities have closed. ${ }^{1}$ COVID-19 is both a biologic threat, and another challenge to the social determinants of health that already disfavor poor and minority women. COVID 19-based fear of hospitals, and hospitals' adoption of protocols that reduce the number of provider-patient contacts during the prenatal period, ${ }^{2}$ have led to diminished opportunities for downstream "saves," and underscore the need for upstream interventions.

Our awareness of nonbiologic contributors to morbidly has grown rapidly over the last decades. The terms "structural racism," "implicit bias," and "social determinants of health" appear much more often in the literature than they did in previous generations. While a provider may not hear those particular words on rounds, if they work in underserved communities, they will hear terms that should raise their specter and help providers to recognize the link between the terms they do hear and adverse events. Every time a patient is called "noncompliant" or "difficult" one should interrogate the circumstances, and consider the possibility that there are issues that affluent individuals do not confront, and which may lead less privileged women to be labeled "noncompliant." Will they lose their placement in a homeless shelter if they do not sign out of the hospital at a certain point to re-establish their residence? Can they afford the bus fares to get to the clinic? And if they finally get to the clinic, are they told to come back at a different time if they are late? Are they "difficult" because their experiences with the health care system have been marked by treatment that was rude, indifferent, or racially insensitive? All of these challenges have been exacerbated by the pandemic. The ability to access healthy food; afford housing; avoid contagion on public transport or in their buildings' small elevators, even to maintain equanimity and avoid weathering in the face of real or perceived microaggressions is undermined by a disease that preferentially infects those whose lives are spent in crowded apartments, and who rely on public transportation to get to low paying but essential jobs.

Even prior to the pandemic, it was hard to ignore the contributions of these problems to morbid outcomes. Hospitals were never, and will never, be able to provide the full sanctuary they should until there is an understanding of the factors that underpin the risks whose consequences are seen full-blown in emergency departments and labor and delivery suites. Those factors begin at a remove of both space and time from the hospital. For example, when reviewing the death of a woman who succumbs to status asthmaticus, it is important to consider that asthma is not randomly distributed across geographic areas. Locations with more pollutants have higher rates of asthma. Communities with more pollutants tend to be poorer communities, often communities of color.

Segregation itself is the residue of affirmative acts designed to relegate certain groups to particular communities and to make it difficult for them either to improve the environment or to leave it. Among the factors that have contributed to the current pattern of color-coded neighborhoods is redlining. ${ }^{3}$ The vestiges of these practices are still felt in these communities, and the continued segregation of these communities is not merely the passive persistence of acts perpetrated generations ago. Residential segregation continues to this day, ${ }^{4}$ and environmental risk factors in poorer communities, such as traffic, air, and noise pollution haven been shown to have a deleterious effect on perinatal outcomes including increased rates of premature birth, stillbirth, and low birthweight. ${ }^{5}$ Other risk factors, for example, obesity and diabetes related to fewer green spaces for exercise and food deserts are the same factors that may accelerate the progression from COVID-19 infection to death from COVID-19.

The COVID-19 pandemic did not create these upstream injuries, but it has brought them to national attention and has exacerbated them. Women may be scared of the crowded buses that they use to go to clinics, and they may be uncomfortable with the new technology platforms being used to replace in-person visits. Indeed surviving relatives have already voiced complaints, not yet fully vetted, that these COVID 19-necessitated changes have contributed to maternal deaths. ${ }^{6}$ Whether these issues are widespread or not, it is clear that more than ever physicians have to link into community organizations so patients are assisted in navigating complex system and in stabilizing their social circumstances, which in turn will allow them to follow medical advice and address illness before they reach an irreversible stage. ${ }^{7}$ The key attribute of the professional in these linkages will not be scholarship or technical skill; there should be the assumption that those will be present. Rather it is a humility that will allow them to learn from the women they serve. William Osler said, "Just listen to the patient, he will tell you the diagnosis." The same is true of communities; they know the issues that thwart the best intended, constructed, and implemented inpatient processes. The health care team must be expanded to include representatives from those communities, individuals who can act as medical Sherpas, and guide women through the medial thicket that often frustrates the best intended but under-resourced woman.

When obstetricians prepare to care for a woman with a complicated cardiac disease, they recognize that medicine cannot be practiced in silos, and highly functioning programs will organize multidisciplinary meetings to assure that everyone is prepared. Similarly, the hospital itself is a silo, and there are outside agents who must play key roles if 
physicians are to assure patients the best possible outcomes. There are opportunities. Community-based organizations, including legal professionals, health-home coordinators, and advocacy groups, surround almost every hospital and can be willing partners with interested departments. The effort needed to forge these links may seem herculean. But, COVID-19 has reminded us that physicians are capable of herculean efforts. If we can battle a viral pandemic, we can confront a social one as well. COVID-19 has made it clearer than ever that it is time to step out of the footprint of our institutions and recognize that there are upstream opportunities to prevent downstream tragedies.

\section{Conflict of Interest}

None declared.

\section{References}

1 Glass K. When maternity wards in black neighborhoods disappear. New York Times. Available at: https://www.nytimes.com/ 2020/05/05/parenting/coronavirus-black-maternal-mortality. html. Accessed May 5, 2020

2 Boelig RC, Saccone G, Bellussi F, Berghella V. MFM guidance for COVID-19. American Journal of Obstetrics \& Gynecology MFM 2020. Doi: 10.1016/j.ajogmf.2020.100106

3 Redlining Mitchell B, Franco J. HOLC "redlining" maps: The persistent structure of segregation and economic inequality. National Community Reinvestment Coalition. Available at: https://ncrc.org/holc/. Accessed May 25, 2020

4 Choi A, Herbert H, Winslow O, Browne A. Long island divided. Newsday November 2019. Available at: https://projects. newsday.com/long-island/real-estate-agents-investigation/ \#open-paywall-message. Accessed May 25, 2020

5 Smith RB, Fecht D, Gulliver J, Beevers SD, Dajnak D. Blangiardo Met al. Impact of London's road traffic air and noise pollution on birth weight: Retrospective population based cohort study. BMJ 2017:359 Doi: 10.1136/bmj.j5299

6 Villarreal A. New York mother dies after raising alarm on hospital neglect. The Guardian May 2, 2020. Available at: https://www. theguardian.com/us-news/2020/may/02/amber-rose-isaac-newyork-childbirth-death. Accessed May 25, 2020

7 Maani N, Galea S. The role of physicians in addressing social determinants of health. JAMA 2020;323(16):1551-1552 